\title{
LÍNGUA PORTUGUESA NA WEB 3.0: RELAÇÕES COMPLEXAS DE ENSINO POR MEIO DOS RECURSOS EDUCACIONAIS ABERTOS (REAs)
}

\author{
FLÁVIO RÔMULO ALEXANDRE DO RÊGO BARROS ${ }^{1}$, \\ ROBERTA VARGINHA RAMOS CAIADO ${ }^{2}$
}

\author{
Universidade Católica de Pernambuco \\ Programa de Pós-graduação em Ciências da Linguagem \\ Rua do Príncipe, 526. Boa Vista. Recife, PE. 50050-900
}

fxdraw@gmail.com, caiado@unicap.br

\begin{abstract}
Resumo. O objetivo deste artigo foi demonstrar que os Recursos Educacionais Abertos (REA) configuram meios de aprendizagem para o ensino de Língua Portuguesa (LP). Embasamo-nos na Teoria da Complexidade (LARSEN-FREEMAN; CAMERON, 2008; LEFFA, 2006); na Teoria da Transposição Informática (BALACHEFF, 1994; CAIADO, 2013); nos REA (WILEY, 2000; BUTCHER, 2011; LEFFA, 2006), e nas Práticas Pedagógicas no meio digital (BONILLA, 2009; MAURI E ONRUBIA, 2010). Nossa análise recaiu sobre duas atividades de LP postadas no ELO, Ensino de Línguas Online. Analisamos essas atividades, identificando como os REA auxiliam na implementação da aprendizagem de LP. Concluímos que as atividades de LP nos REA possibilitam integrar sistemas complexos em favor de um sistema maior, a educação.
\end{abstract}

Palavras-chave: linguagem; tecnologias digitais da informação e comunicação; web 3.0; recursos educacionais abertos.

\begin{abstract}
The objective of this article was to demonstrate that the Open Educational Resources (OER) constitute means of learning for the teaching of Portuguese Language (LP). We are based on the Complexity Theory (Larsen-Freeman, Cameron, 2008, Leffa, 2006); In Computer Transfer Theory (BALACHEFF, 1994; CAIADO, 2013); in the OER (WILEY, 2000; BUTCHER, 2011; LEFFA, 2006), and Pedagogical Practices in the digital environment (BONILLA, 2009; MAURI and ONRUBIA, 2010). Our analysis fell on two LP activities posted at ELO, Teaching Online Languages. We analyze these activities, identifying how OER assist in the implementation of LP learning. We conclude that LP activities in OER make it possible to integrate complex systems in favor of a larger system, education. Keywords: language; digital information and communication technologies; web 3.0; open educational resources.
\end{abstract}

\footnotetext{
${ }^{1}$ Mestrando em Ciências da Linguagem pela Universidade Católica de Pernambuco.

2 Doutora em Educação pela Universidade Federal de Pernambuco. Coordenadora do Programa de PósGraduação em Ciências da Linguagem da Universidade Católica de Pernambuco.
} 


\section{Introdução}

Contemporaneamente, a Linguagem, as Tecnologias Digitais da Informação e Comunicação (doravante TDIC) e as Práticas Pedagógicas estão cada dia mais imbricadas. Isso porque o avanço das tecnologias digitais, frente à Web 3.0, e os usos cotidianos dessas tecnologias pelos sujeitos, modificam a linguagem, demandam da escola, na figura de seus professores, novas práticas que privilegiem e levem à reflexão desses usos sociais.

Dessa forma, o objetivo deste artigo é demonstrar que os REA configuram meios de aprendizagem para o ensino de Língua Portuguesa, dentro da visão da Web 3.0, a partir dos desafios propostos para a escola na era digital, na qual vários sistemas, por demais complexos, proporcionam uma nova perspectiva para o ensino.

Para tal fim, nos embasamos na Teoria da Complexidade (LARSEN-FREEMAN; CAMERON, 2008; LEFFA, 2006; OLIVEIRA, 2009; HUEY, 1908; BYBEE, 2010; BECKNER et al., 2009); na Teoria da Transposição Informática (BALACHEFF, 1994a, 1994b; CAIADO, 2013) e nos Repositórios Digitais - REA (WILEY, 2000; BUTCHER, 2011; LEFFA, 2006; SANTOS, 2013) - tudo isso relacionado às Práticas Pedagógicas no meio digital (BONILLA, 2009; MAURI; ONRUBIA, 2010).

Entendemos que os REA configuram oportunidades para o professor transpor as aulas para a web de forma reflexiva, dinâmica e aproveitar o tempo que os alunos navegam na internet para a educação; tendo em vista que eles utilizam a Web 3.0 através de sites, redes sociais, blogs, vlogs, wikis e ambientes de aprendizagem possibilitando um acesso mais democrático, gratuito e atrativo para os estudantes.

Nossa análise recaiu sobre duas atividades de Língua Portuguesa postadas em um Repositório Digital - o ELO (Ensino de Línguas Online). Analisamos essas atividades, produzidas por dois professores, a partir de suas práticas pedagógicas, observando como os REA podem ajudar na aprendizagem de LP.

Concluímos que aprender a utilizar as estratégias linguísticas no REA possibilita transformar as TIDIC como aliadas para a aquisição do conhecimento na disciplina de Língua Portuguesa, além de integrar sistemas complexos em favor de um sistema maior - a educação.

\section{A Teoria da Complexidade no século XXI}

A Teoria da Complexidade para Larsen-Freeman e Cameron (2007) é considerada como uma metáfora ou uma suprateoria para sistemas na linguística aplicada. Segundo as autoras a Teoria da Complexidade surge em diversas áreas do conhecimento. Um dos pesquisadores mais influentes da teoria é o biólogo - Conrad Waddington (1940) e a Teoria da Complexidade pode, também, embasar estudos em filosofia, epistemologia, linguística, pedagogia, matemática, química, física, meteorologia, estatística, sociologia, economia, arquitetura, medicina, psicologia, informática ou em ciências da computação ou da informação. Os princípios da teoria da complexidade são explicados, desenhando 
no trabalho nas ciências biológicas, psicológicas e sociais. Vivemos em um mundo complexo e em constante mudanças que tornam a vida difícil e buscamos a tranquilidade na rotina. Para as autoras, "a mudança e a heterogeneidade são fundamentais para a teoria da complexidade e às ressonâncias que encontramos com os sistemas linguísticos aplicados" (LARSEN-FREEMAN; CAMERON, 2007, p. 1).

Paiva (2011) vê a complexidade como uma nova metáfora que atravessa diferentes campos do conhecimento e tornou-se um novo paradigma da ciência disponibilizando conceitos que facilitam o entendimento de diferentes fenômenos nas mais várias áreas do conhecimento incluindo a Linguística Aplica.

Mas o que vem a ser a Teoria da Complexidade? Leffa (2006, p. 29) a define como: "Um conjunto de ideias que incorpora os princípios de diversas teorias, entre as quais se destacam os Sistemas Complexos, a Teoria do Caos, o Pensamento Complexo e a Teoria da Atividade". Para muitos, a Teoria da Complexidade conota algo complicado, difícil, devido ao vocábulo complexidade, porém Oliveira (2009, p. 15) conceitua complexidade, a partir do latim complexu, como: "uma ideia de qualidade intricada ou composta". O autor afirma que "a palavra caracteriza aquilo que é composto de partes que se relacionam de maneira intricada. No seu uso corriqueiro, o complexo é muitas vezes sinônimo de "complicado"” (OLIVEIRA, 2009, p. 15).

Entendemos por Teoria da Complexidade o estudo dos sistemas complexos que são dinâmicos e não seguem caminhos lineares e incorporam, dentro de uma determinada área do conhecimento, várias disciplinas interligadas. $\mathrm{E}$ em nosso estudo a interdisciplinaridade entre a linguística e a informática é uma clara prova de sistemas por demais complexos que se interligam.

A Teoria da Complexidade pretende explicar como as partes que interagem em um sistema complexo dão origem ao comportamento coletivo do sistema. Para LarsenFreeman (2007, p. 3): "os sistemas complexos são compostos de elementos ou agentes que são de muitos tipos diferentes e que interagem em diferentes maneiras".

Em relação à língua, podemos afirmar que ela é complexa porque depende de uma série de fatores para ser apreendida pelo ser humano. Huey (1908) reforça essa ideia da complexidade da língua quando afirma que a leitura é um sistema tão complexo que para entendê-la seria necessário entender o funcionamento do cérebro.

Leffa (2006), por sua vez, diz que a convergências de várias áreas do conhecimento para a explicação de um fenômeno é bastante difícil, ele exemplifica afirmando que para descrever a aprendizagem da língua é necessário recorrer a diversas áreas do conhecimento como a Linguística, a Linguística Aplicada, a Psicologia, a Pedagogia entre outras.

Bybee (2010) propõe que a língua é um sistema adaptativo complexo. Ela usa uma metáfora para explicar que um idioma é mais parecido com uma duna de areia que está em constante movimento do que uma estrutura rígida, fixa como um edifício. O idioma possui uma enorme variação e gradiente. 
Segundo Beckner et al. (2009) uma das características da linguagem como um Sistema Complexo Adaptativo (SCA) é que a linguagem existe tanto no indivíduo como idioleto quanto na comunidade de usuário pela linguagem social. A linguagem emerge desses dois indivíduos distintamente, porém interdependente. O idioleto surge no uso da linguagem do indivíduo através da interação social com outros indivíduos, propiciando o surgimento da linguagem social que é o resultado da interação dos idioletos.

Para entender como os sistemas complexos são integrados nas práticas pedagógicas no século XXI, utilizando as TIDIC como meio de ensino da língua/linguagem, especificamente LP, encontramos em Leffa (2006, p. 15) a definição de transdisciplinaridade, a partir do que propõe Nicolescu (1999), porque assim como a teoria complexa, os sistemas não podem ficar isolados: "A transdisciplinaridade é o estágio final de uma visão evolucionista de ciência que começa com a disciplinaridade, evolui para multidisciplinaridade, daí para a interdisciplinaridade e finalmente para a transdisciplinaridade". A primeira etapa, a disciplinaridade nasce da própria relação, ao mesmo tempo isolada, entre a disciplina e seu objeto; a segunda etapa, a multidisciplinaridade é o processo no qual diferentes disciplinas têm um olhar para o mesmo objeto, mas de diferentes perspectivas, mesmo sendo o objeto de estudo comum a todas as disciplinas, elas ainda são compartimentadas, isoladas, sem nenhuma interação objeto-disciplinas; por sua vez, na etapa da interdisciplinaridade há interação: metodológica, de objetivos, conceitual, entre as disciplinas que estudam o mesmo objeto; na quarta etapa, denominada de transdisciplinaridade, parte-se do objeto e não mais das disciplinas, invertendo-se a relação na tentativa de apagamento das fronteiras impostas pela tradição da ciência, que é dividida em áreas do conhecimento.

É a transdisciplinaridade que observamos neste artigo, a partir dos macros sistemas: a Linguagem, as TIDIC e as Práticas Pedagógicas que constituem, num todo, a Teoria da Complexidade na Linguagem.

\section{A Teoria da Transposição Informática}

A Transposição Informática foi inicialmente enunciada pelo estudioso francês em Educação Matemática Nicolas Balacheff. No âmbito da sociedade informatizada, o teórico (BALACHEFF, 1994a, p. 12) enuncia em sua teoria da Transposição Informática (TI), também denominada de teoria da Transposição Computacional, a "adaptação dos saberes que se aplicam aos ambientes digitais de aprendizagem na internet, na elaboração de softwares ou na criação de dispositivos de inteligência artificial". A pesquisa desse autor busca conhecer o processo de aprendizagem e de construção do conhecimento, em educação matemática, utilizando-se de tecnologias digitais de informação e comunicação (TDIC).

A TI, segundo o próprio autor, estuda a transposição dos saberes sábios para o meio digital, de acordo com as exigências específicas dos meios eletrônicos. "Em outras palavras, é o processo em que o conhecimento, tendo origem em um saber sábio de referência e sendo dirigido para determinado saber aprendido pelo estudante, passa, necessariamente, por uma modelização informatizada" (BALACHEFF, 1994b, p. 370). A base das pesquisas empreendidas por Balacheff está contida no modo como ocorre a 
aprendizagem e a construção do conhecimento, utilizando-se, para isso, das tecnologias digitais da informação e comunicação e criando modelos de aprendizagem nelas embasados. No nosso entendimento, a TI parte de um sistema de conhecimento de uma determinada área do saber para outro sistema - regido por tecnologias digitais e pela $\mathrm{Web}$ 3.0 - relacionando, assim, esses saberes no meio digital.

Dessa forma, a Transposição Informática vem a ser o processo de transformação do saber sábio atrelado às TDIC. Balacheff (1994a) entende que os ambientes digitais de aprendizagem são, também, espaços de aprendizagem e oferecem novos objetos de ensino. Acreditamos que a teoria da TI pode ser utilizada em qualquer área do conhecimento; na disciplina Língua Portuguesa, por exemplo, a leitura de hipertextos hipermodais ou a produção de gêneros discursivos digitais poderiam ser exemplos de atividades em ambientes digitais de aprendizagem.

Balacheff (1994b), também, introduz o termo competência pluridisciplinar, pois acredita que a TI não representa, apenas, as alterações, modificações e adaptações isoladas pelas quais passa um conhecimento ao ser ensinado a partir de uma máquina, o computador. Existem restrições físicas, disciplinares, dos sujeitos envolvidos, para a devida comunicação entre os saberes e, posterior, efetivação, da aprendizagem. Corroborando Balacheff, afirmamos que a TI é pluridisciplinar.

A título de enriquecimento, acrescentaríamos que muitas vezes, especificamente com relação aos ambientes e dispositivos digitais, é o aluno o responsável por ensinar ao professor o conhecimento adquirido, conhecimento esse advindo das práticas sociais experienciadas por esse aluno, fora da escola, no que diz respeito às TDIC. Nesse caso, o aluno seria o detentor do saber advindo das práticas sociais de uso das tecnologias digitais e transformaria esse saber, no saber efetivamente ensinado ao professor da disciplina ou a outros alunos (colegas de turma), ao iniciá-los nas TDIC, ou ao interagir com eles (professores e colegas) em ambientes digitais de aprendizagem, durante as atividades no laboratório de informática ou na sala de aula: navegar na internet, acessar sites, criar sites, criar blogs, postar fotografias, formatar textos digitais no Word, enviar e-mails, ler hipertextos.

Consideramos que os professores ainda requerem um apoio pluridisciplinar para a ampliação de suas competências no uso do ambiente digital ensejando um repensar da prática pedagógica, nos três níveis do processo da transposição: saber sábio (enquanto pesquisadores), saber a ensinar (enquanto autores) e saber ensinado (enquanto professores).

A figura 1, que ilustra as ideias de Balacheff (1994a), enfatiza o fato de que, na TI, o saber a ensinar e os objetos de ensino sofrem transformações ao serem "modelados computacionalmente", devido ao meio no qual se encontram - digital - e transformam-se em saberes "implementados". Outro fato relevante, observável no esquema de Balacheff, diz respeito à aprendizagem advinda da interação aluno/máquina. Em decorrência dessa interação, o saber sábio, necessariamente, passa por adaptações para fins de ensinoaprendizagem, considerando-se as novas ferramentas digitais e, consequentemente, as possibilidades dos hardwares e softwares disponíveis (BALACHEFF, 1994a). 


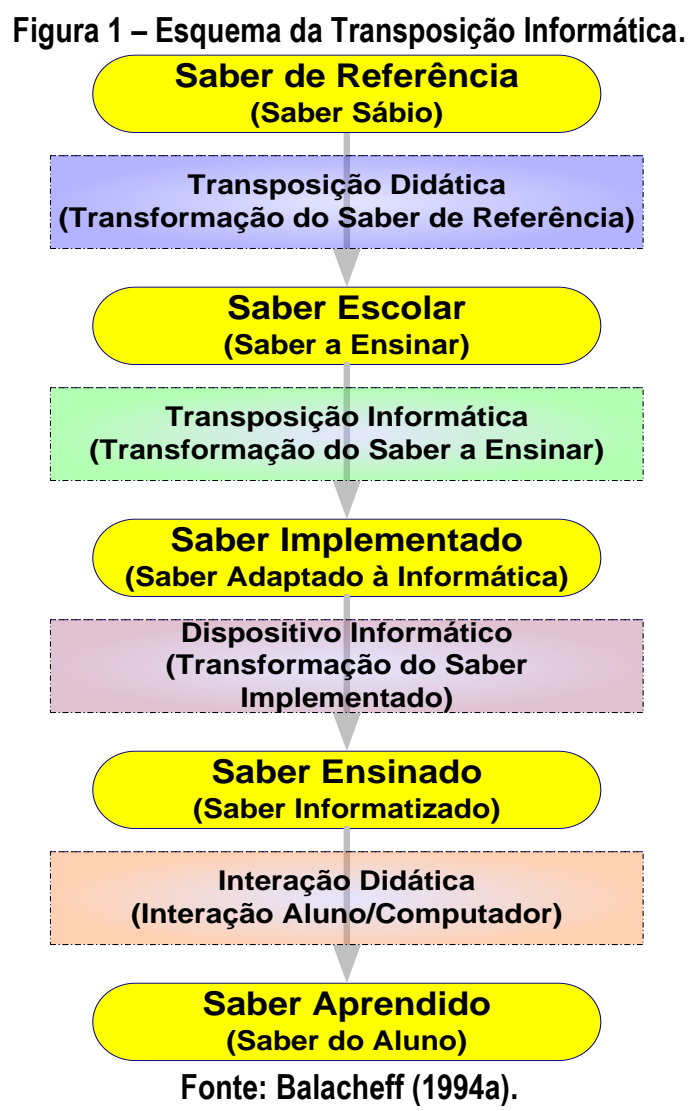

O esquema da Transposição Informática parte do Saber de Referência (saber sábio) que se modificaria em Saber a Ensinar (saber escolar). A partir da mudança do meio no qual se realizaria a aprendizagem - meio digital (ambiente digital de aprendizagem) - ocorreria a TI, que transformaria o Saber a Ensinar em Saber Adaptado à Informática - um saber implementado. Por sua vez, o Saber Implementado passaria por certa transformação ao entrar em contato com o Dispositivo Informático (com o hardware e software). O Saber efetivamente Ensinado, no final da cadeia da TD, passaria a ser um Saber Informatizado, que na interação do aluno com a máquina/computador produziria o Saber Aprendido - apreendido pelo aluno - o saber do aluno.

Acreditamos que a TI clareia o processo de transformação dos saberes no meio digital, quando esse processo envolve sistemas complexos que interagem em favor do ensino de LP. No próximo tópico, apresentaremos a Web 3.0, que é inerente às TDICS.

\subsection{A evolução da Web 1.0 à 3.0}

Nos últimos quinhentos anos, diversas descobertas contribuíram para o salto de desenvolvimento intelectual da humanidade, desde a tipografia de Guttemberg em 1436, passando pela invenção da eletricidade por Tomas Edison em 1879, a invenção do telégrafo e do telefone por Alexandre Gran Bell, o desenvolvimento do rádio por Guglielmo Marconi, e mais centenas de outras descobertas e invenções que facilitaram a vida de milhares de pessoas no mundo inteiro. Porém, uma das mais importantes 
invenções da humanidade, descoberta no século XX, é sem dúvida a "World Wide Web" (www).

Em seu livro Waving the web, Bernes-Lee (2000, p. 123) afirma que "A Web é mais uma criação social do que uma questão técnica. Eu projetei-a para um efeito social - para ajudar as pessoas a trabalharem juntas - e não como um brinquedo técnico."3 A web não foi feita para fins comerciais e nem com objetivos financeiros, mas sua criação tinha o objetivo social de deixar as pessoas conectadas para que elas pudessem ficar juntas de algum modo. A web mudou em pouco tempo a forma de vida, dos seres humanos, o modo de interagir em sociedade, a linguagem, a educação, alcançando um patamar inimaginável.

O termo web muitas vezes é usado como sinônimo de internet, mas não são a mesma coisa. A confusão acontece porque é a web que leva as pessoas à internet. A internet é uma rede que conecta milhões de computadores pelo mundo e a web é a ferramenta que proporciona o acesso à rede através de navegadores (browsers) criada por Tim Berners-Lee. O objetivo de Berners-Lee (2000) era desenvolver um programa que permitisse a criação, a navegação e a edição de páginas de hipertexto.

Com o passar dos anos, a web evoluiu, algumas características foram aprimoradas e novas foram surgindo, proporcionando melhorias no sistema que continua em constante transformação. Segundo Aghaei, Nematbakhsh, Farsani (2012, p. 1):

Muito progresso tem sido feito sobre a web e tecnologias relacionadas nas últimas duas décadas. Web 1.0 como uma web da cognição, web 2.0 como uma web da comunicação, web 3.0 como uma web de cooperação e web 4.0 como uma a web de integração são introduzidas como quatro gerações semelhantes da web desde o seu advento. ${ }^{4}$

Atualmente, estamos na terceira geração da web. Para os autores supracitados a Web 4.0 é algo que ainda estaria por vir, logo não nos deteremos em apresentá-la. Fazemos apenas uma ressalva de que com a velocidade dos acontecimentos, acreditamos que a Web 4.0 não tardará a chegar. A Web 1.0 é a primeira geração da web criada por Berners-Lee em 1990. Considerada um sistema de cognição, tinha como função apenas fazer leituras dos textos. Era, de início, utilizada por universidades, pelo mercado comercial com o objetivo de informar os negócios das empresas e a para a comunicação de pessoas, de forma indireta e não simultânea. Um dos poucos recursos existentes era a realização de downloads dos conteúdos disponíveis na web, e-mails e chats.

As informações eram estáticas, visuais, o usuário não tinha o controle das informações, eram passivos, porém com responsabilidade na navegação e localização de conteúdos postados por poucos, a exemplo dos portais UOL, Terra e AOL e dos diretórios Yahoo e Cadê, e consumidos por muitos. Sua grande virtude foi a democratização do acesso à informação (SANTOS, 2013).

\footnotetext{
3 Tradução nossa do original: "The Web is more a social creation than a technical one. I designed it for a social effect - to help people work together - and not as a technical toy".

${ }^{4}$ Tradução nossa do original: "Much progress has been made about the web and related technologies in the past two decades. Web 1.0 as a web of cognition, web 2.0 as a web of communication, web 3.0 as a web of co-operation and web 4.0 as a web of integration are introduced such as four generation of the web since the advent of the web.
} 
Também conhecida como web das redes sociais, a Web 2.0 surge com a ideia de upload de arquivos. Na segunda geração da web, os usuários, além de ler, podiam também escrever. As buscas ficaram mais dinâmicas, estavam chegando a um patamar que Tim Berners-Lee vislumbrara quando criou a web. Ele queria que a web dinamizasse as buscas dos usuários através de máquinas mais rápidas e que tivessem uma inteligência artificial. As redes sociais estabeleceram-se nesse período. Chats, blogs, wikis, marshups e serviços como MSN, Orkut, ICQ foram importantíssimos para o surgimento de uma internet colaborativa. Nesse período, também, o Google surge como o maior site de busca e outras empresas aparecem possibilitando ao usuário criar e interagir. As curtidas no Facebook e o "joinha" do Youtube, as curtidas do Instagram despertam no usuário a ideia de intervir nas postagens e marcam a dinamicidade e interação da web.

Ainda em 1998, Tim Berners-Lee profetizava como seria a internet no futuro: "a $W e b$ foi desenvolvida não apenas com o objetivo de realizar a comunicação entre os seres humanos, mas as máquinas deveriam estar habilitadas para ajudar as buscas na rede em

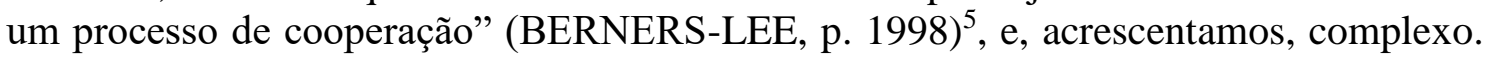
Porém, ele percebeu que o maior obstáculo era o fato de as informações serem desenvolvidas por seres humanos.

A Web Semântica, como ficou conhecida a Web 3.0, desenvolve informações através de um banco de dados unificado e mais direcionado ao desejo dos usuários, facilitando o trabalho dos humanos. Quando buscamos o significado básicos do termo semântica, compreendemos melhor o que vem a ser Web Semântica. O termo semântica vem do grego sêmantiké $\bar{e}$ e tem o sentido de "que indica, que significa, que faz conhecer", ou seja, a Web Semântica interliga o sentido das palavras tornando compreensível tanto para os humanos quanto para as máquinas. A quantidade de dados disponível na rede é infinito e, atualmente, são manipulados pelos computadores. A Web Semântica é uma Web de informações acionáveis derivadas de dados através de uma teoria semântica para interpretar os símbolos.

Na web semântica, a web deixou de ser um grande livro hiperlinkado, no qual pessoas podiam pesquisar, navegar, visualizar e ler informações. A Web 3.0 possibilita que os computadores interpretem ações dos internautas, estabeleçam inferências e relações na web.

\subsection{Os REA e o ensino de Língua Portuguesa}

Originalmente chamado de Open Educational Resources, ou OER, em um evento promovido pela UNESCO, no Massachusetts Institute of Technology (MIT), em 2002, o termo foi traduzido em 2006, no Brasil, como Recursos Educacionais Abertos - REA -

\footnotetext{
${ }^{5}$ Tradução nossa do original: "The Web was designed as an information space, with the goal that it should be useful not only for human-human communication, but also that machines would be able to participate and help". Retirado do artigo Semantic Web Road Map, 14 out. 1998. Disponível em https://www.w3.org/DesignIssues/Semantic.html. Acesso em 12 de maio de 2016.

6 Significado retirado do Grande Dicionário Houaiss, disponível em https://houaiss.uol.com.br/pub/apps/www/v3-3/html/index.php\#2.
} 
num período em que aumentava o ensino a distância e sua participação no ensino superior (SANTOS, 2013).

O termo REA foi implantando graças ao resultado de dois projetos financiados pela William and Flora Hewllet foundation: o MIT OpenCourseWare (<http://ocw.mit.edu>), da Universidade de Massachussets, nos Estados Unidos, e o OpenLearn (Open University, do Reino Unido), que lançou um repositório de REA, com acesso gratuito, com $5 \%$ de todo o conteúdo produzido pela universidade na internet, sob licença Creative Commons e com tecnologias da Web 2.0. Desse modo, uma nova maneira de ensinar e aprender começou a surgir.

Na sociedade midiatizada, os Recursos Educacionais Abertos - REA - são algo relativamente novo, principalmente na escola, relacionados às práticas pedagógicas dos professores de LP. Os REA são frequentemente chamados de repositórios digitais de objetos de aprendizagem ou conteúdo aberto. Eles são elementos de um novo tipo de instrução baseada em computador e fundamentada no paradigma orientado aos objetos da ciência da computação. Surgem como uma ferramenta de apoio ao professor - FAP - e tornam-se um meio de ensino-aprendizagem, visando desenvolver inúmeras atividades no meio digital.

Os REA são sistemas complexos que podem ser reutilizados em múltiplos contextos. Por serem desenvolvidos na Web 3.0, através da internet, permitem o acesso de inúmeras pessoas simultaneamente, no que diferem de objetos de ensino tradicionais (WILEY, 2000). Dessa forma, os objetos de aprendizagem podem ser modificados, incrementandos, melhorando e desenvolvendo novas versões, tendo como características, segundo Leffa (2006), a granulidade, a reusabilidade, a interoperabilidade e a recuperabilidade. $\mathrm{O}$ conceito de granulidade está baseado nas peças de montar do jogo Lego (WILEY, 2000), ou seja, o professor pode criar apenas uma simples atividade para ajudar no aprendizado da disciplina e, aos poucos, poderá desenvolver outras atividades mínimas que juntas formarão um conteúdo completo. O conceito da reusabilidade incide nas atividades postadas, que ficam disponíveis para que qualquer pessoa possa usá-las ou modificá-las, aprimorando o que já foi feito. Uma terceira característica dos REA é a interoperabilidade, por ser desenvolvido em nuvem, graças a Web 3.0 que proporciona, hoje, interação entre homem e máquina. Pensando na interoperabilidade, as atividades podem ser acessadas de qualquer dispositivo, podem ser realizadas em qualquer lugar, através dos smartphones dos alunos, no laboratório de informática da escola, em qualquer sistema operacional ou até mesmo dentro da sala de aula. Por fim, a última característica dos REA, a recuperabilidade, que configura-se na possibilidade de retornar ou recuperar o conteúdo desejado quantas vezes julgar necessário. Interessante ressaltar que o acesso, o planejamento das atividades e as postagens, tudo, pode ser feito em qualquer sistema operacional Windows, Linux, Mac.

Duas importantes iniciativas foram dadas para o desenvolvimento do REA, segundo Santos (2013, p. 21):

em 2001 marcaram o desenvolvimento do movimento REA: a fundação da creative commons (<http://www.creativecommons.org $>$ ) e o consórcio opencourseWare <http://www.ocwconsortium.org/>). A primeira possibilita aos detentores de direitos autorais escolherem de quais direitos desejam abrir mão, permitindo que usuários de conteúdos 
educacionais copiem, adaptem, traduzam e compartilhem recursos livremente. A segunda iniciativa envolve diversas instituições de ensino em todo o mundo que se reuniram em um consórcio para fomentar o movimento REA por meio da produção de conteúdos e aconselhamento sobre políticas, promoção e pesquisa.

Essas iniciativas facilitaram a propagação de conteúdos educacionais. Os materiais disponibilizados de forma integral com a praticidade do compartilhamento através da internet agregam valores incalculáveis ao aprendizado.

A aprendizagem apoiada nos REA, disponibilizados gratuitamente, possibilita descentralizá-la do professor e guiá-la de acordo com os objetivos e interesses dos aprendizes. $\mathrm{O}$ uso dos REA ocorre de forma tímida, principalmente, no ensino médio e fundamental, níveis nos quais, ainda, prevalece, em grande parte das escolas, o ensino formal e convencional, orientado por metodologias educacionais centradas na teoria somente. Entendemos que os REA configuram meios de ensino-aprendizagem, oportunizando ao professor transpor as aulas para a web de forma reflexiva, participativa e dinâmica; e, ao aluno, aprendizagem motivada, relacionada às suas práticas de uso sociais, aproveitando o tempo e o espaço que navegam na internet para a educação.

\section{Perfil, condições e competências dos professores em ambientes digitais}

Os professores, que são agentes importantes e responsáveis diretos pela transposição dos saberes a serem efetivamente ensinados na escola deverão, também, desenvolver competências que atendam a essas novas demandas da sociedade da informação.

Eles deveriam, antes de tudo, no nosso ponto de vista, compreender o porquê do uso das novas tecnologias na escola, através da reflexão, individual e em grupo; deveriam, também, discutir sobre como essa tecnologia poderia se tornar meio de aprendizagem na disciplina que ministram e, não somente, recurso didático, o que os levaria, tão somente, a utilizar a máquina pela máquina.

Concordamos que as formações continuadas que os professores recebem para trabalhar com a máquina - o computador - são importantes, mas questionamos o teor ou o foco dessas formações. Geralmente, os professores são orientados, apenas, para utilizar o recurso informático: ligar e desligar o computador, mexer no mouse, colocar um CD para rodar no computador, trabalhar no word ou no excel.

Acreditamos, assim como Bonilla (2005, p. 100):

[...] que o professorado deve compreender as características e potencialidades das tecnologias, tendo claro que compreender significa mais do que ser capaz de fazer funcionar, significa inseri-las no contexto contemporâneo, penetrar nessa nova linguagem, nessa nova lógica, nesse novo modo de ser, pensar e agir. 
Ainda hoje, podemos afirmar que não faz parte da bagagem teórico-prática dos professores os conceitos de hipertextualidade, links, home page, hipermodalidade e os usos advindos deles, o que se reflete em sua prática pedagógica. Esse fato justifica nossa crença na necessidade da incorporação ou entendimento da Teoria da Transposição Informática no espaço escolar.

A partir da compreensão proposta por Mauri e Onrubia (2010, p. 119) sobre o estado das competências que os docentes deveriam adquirir para conseguir integrar as novas TDIC à educação, às suas práticas pedagógicas, elaboramos o quadro 1, que nos dá uma visão globalizante das diferentes compreensões do processo de ensino no meio digital.

Objetivamos, da mesma forma que os autores, "traçar um conjunto do perfil, condições e competências do professor nos novos ambientes de aprendizagem mediados pelas TDIC que seja o mais amplo e integrador possível” (MAURI; ONRUBIA, 2010, p. 120).

Interpretamos, que o perfil do professor advém da concepção do processo de ensino, mediado pelas TDIC, que ele possui. Dessa forma, em uma:

a) concepção centrada na dimensão tecnológica, apenas, bastaria, ao professor, dominar a máquina pela máquina, ou seja, as tecnologias "per si";

b) concepção centrada no acesso à informação exigiria um professor que estimulasse uma postura crítica por parte do aluno diante da informação e que soubesse aproveitar esse tipo de acesso à informação, em rede, na rede;

c) concepção centrada em novas metodologias exigiria um professor designer, no que tange à busca ou confecção de materiais e recursos diferentes, de propostas de aprendizagem;

d) concepção centrada na construção do conhecimento, o professor deveria colocar a tecnologia a serviço do aluno, criando um contexto de atividade que tenha como resultado a reorganização de suas funções cognitivas, acompanhando o processo de aprendizagem do aluno, enquanto mediador da aprendizagem, envolvendo-se em diferentes graus.

Quadro 1 - Modelos ou Esquemas do Processo de Ensino Mediado Pelas TDIC.

\begin{tabular}{|c|c|c|}
\hline $\begin{array}{l}\text { Concepção do } \\
\text { Processo de } \\
\text { Ensino } \\
\text { mediado pelas } \\
\text { TDIC } \\
\end{array}$ & Papel do Professor & Competências a serem desenvolvidas no professorado \\
\hline $\begin{array}{l}\text { Centrada na } \\
\text { dimensão } \\
\text { tecnológica }\end{array}$ & $\begin{array}{l}\text { - Dominar as } \\
\text { tecnologias "per si”. }\end{array}$ & 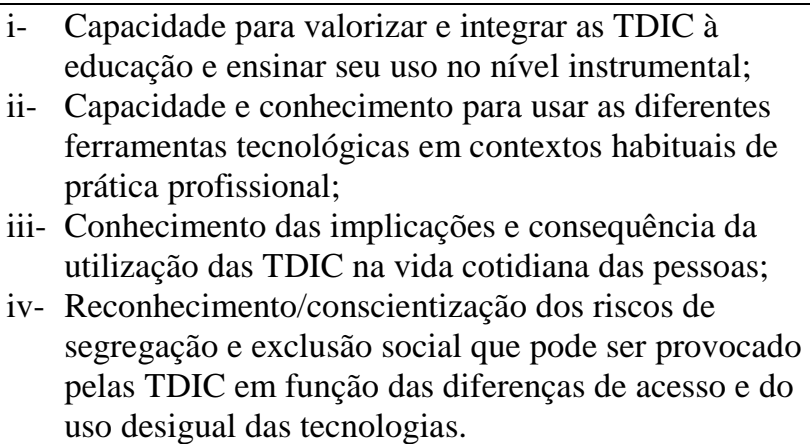 \\
\hline
\end{tabular}




\begin{tabular}{|c|c|c|}
\hline $\begin{array}{l}\text { Centrada no } \\
\text { acesso à } \\
\text { informação }\end{array}$ & $\begin{array}{l}\text { - Tirar proveito da } \\
\text { riqueza desse tipo } \\
\text { de acesso à } \\
\text { informação; } \\
\text { - Incentivar uma } \\
\text { postura crítica, por } \\
\text { parte do aluno, } \\
\text { diante do material } \\
\text { acessado/pesquisad } \\
\text { o/encontrado. }\end{array}$ & 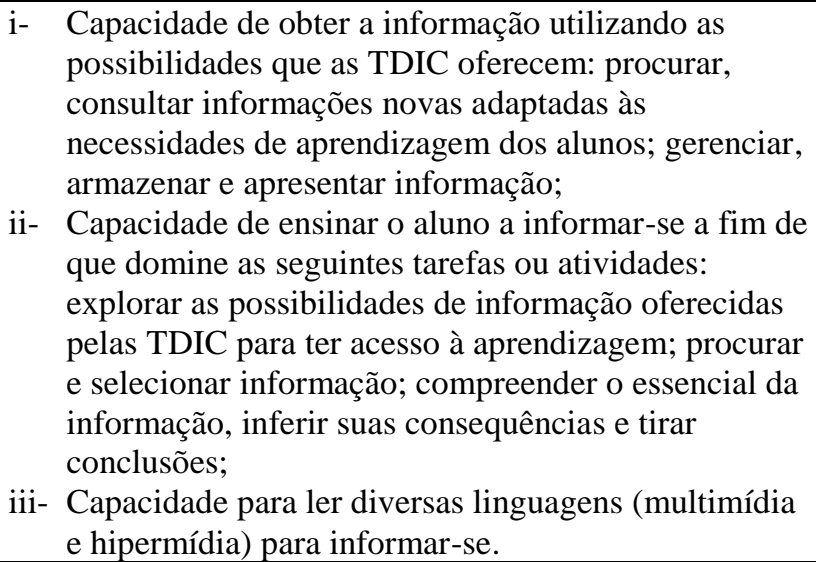 \\
\hline $\begin{array}{l}\text { Centrada em } \\
\text { novas } \\
\text { metodologias }\end{array}$ & $\begin{array}{l}\text { - Tornar-se } \\
\text { "Designer" de } \\
\text { propostas de } \\
\text { aprendizagem. }\end{array}$ & $\begin{array}{l}\text { i- } \quad \text { Capacidade para procurar materiais e recursos } \\
\text { diferentes referentes às TDIC; } \\
\text { ii- } \quad \text { Capacidade para projetar materiais com as TDIC. }\end{array}$ \\
\hline
\end{tabular}

Quadro 1 - Modelos ou Esquemas do Processo de Ensino Mediado Pelas TDIC (continuação).

\begin{tabular}{|c|c|c|}
\hline $\begin{array}{l}\text { Concepção do } \\
\text { Processo de } \\
\text { Ensino mediado } \\
\text { pelas TDIC } \\
\end{array}$ & $\begin{array}{l}\text { Papel do } \\
\text { Professor }\end{array}$ & Competências a serem desenvolvidas no professorado \\
\hline $\begin{array}{l}\text { Centrada na } \\
\text { Construção do } \\
\text { conhecimento }\end{array}$ & $\begin{array}{l}\text { - Colocar a } \\
\text { tecnologia a } \\
\text { serviço do } \\
\text { aluno, } \\
\text { criando um } \\
\text { contexto de } \\
\text { atividade que } \\
\text { tenha como } \\
\text { resultado a } \\
\text { reorganização } \\
\text { de suas } \\
\text { funções } \\
\text { cognitivas; } \\
\text { - Acompanhar } \\
\text { o processo de } \\
\text { aprendizagem } \\
\text { do aluno, } \\
\text { mantendo } \\
\text { diferentes } \\
\text { graus de } \\
\text { envolvimento } \\
\text { no processo, } \\
\text { cedendo o } \\
\text { controle ao } \\
\text { aluno, quando } \\
\text { esse é capaz } \\
\text { de assumi-lo. }\end{array}$ & 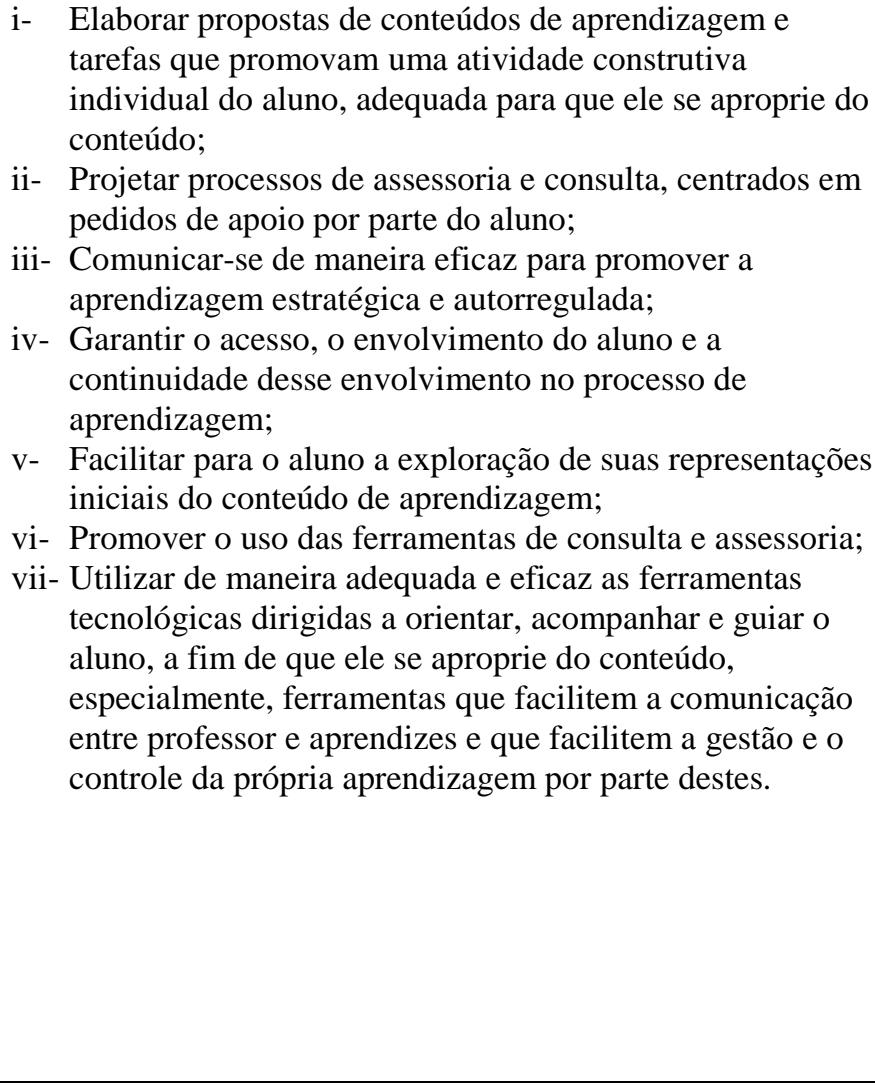 \\
\hline
\end{tabular}

FONTE: Elaborado pela pesquisadora a partir de: Mauri e Onrubia (2010, p. 118-126).

Concluímos que, para incorporar as novas TDIC à prática pedagógica, os professores necessitariam planejar, vivenciar, usar, navegar, experienciar as novas 
tecnologias da informação e comunicação, percorrendo, muitas vezes, os caminhos propostos aos alunos, na Web 3.0, sem preconceitos, orientando e deixando-se orientar pelos seus educandos em uma relação interativa ininterrupta.

Cumpre ao professor, neste contexto midiático, o papel de mediador ${ }^{7}$, na atividade construtiva do aluno, utilizando, enquanto meio de aprendizagem, no caso, de Língua Portuguesa, as novas TDIC. Aproveitar tudo que a internet e a web podem proporcionar nessa nova forma de ensinar é de extrema importância.

\section{Discussão}

Diante dessas constatações, fizemos uma busca pela internet e encontramos um repositório digital denominado $\mathrm{ELO}^{8}$ - Ensino de Línguas Online - que foi desenvolvido especialmente para esse fim, o ensino de línguas e para que o professor possa colocar em prática todas as características dos REA.

No site ELO, o acesso aos objetos já postados é possível através dos meta-dados, um sistema de catálogo ou biblioteca virtual disponível para o acesso imediato daquilo que se deseja. Tudo que foi produzido fica disponível para todos. Para o ensino de Língua Portuguesa, em REA, por exemplo, é possível utilizar recursos textuais e estratégias semânticas, morfossintáticas, fonológicas e ortográficas de maneira integrada.

Na figura 1, é possível observar a página inicial do ELO. O professor cadastrado pode utilizar todas as possibilidades disponíveis no REA e desenvolver qualquer sequência relacionada ao ensino de Língua Portuguesa ou Segunda Língua.

Os recursos disponíveis nos REA permitem que o professor aborde os conteúdos de interesse em um universo móvel, de modo a tornar a aquisição do conhecimento parte integrante das vivências de mundo. Desse modo, o professor aprende a utilizar estratégias linguísticas em um universo destinado a integrar pessoas, e porque não - a partir dos fundamentos propostos pela Teoria da Complexidade - integrar conhecimento.

A primeira atividade proposta no ELO - figura 3 - sobre o Novo Acordo Ortográfico da Língua Portuguesa, pode ser entendida como um REA em formato de jogo da memória, criado no meio digital; utiliza-se de recursos multimodais, como imagens e textos, links que conduzem a outras páginas e hipertextos, além das habilidades técnicas impostas pela máquina, pela navegação na Web 3.0, concorrendo para uma Transposição Informática, conforme propõe Balacheff (1991).

\footnotetext{
7 Outros autores (BERGE, 1995; HEPP, 2003; MCPERSON; NUNES, 2004; SALMON, 2002; MONEREO, 2005; SAVERY, 2005) referem-se ao professor $e$-mediador em quatro âmbitos: o pedagógico (desenvolvimento de um processo de aprendizagem virtual eficaz), o social (desenvolvimento de um ambiente de aprendizagem com um clima emocional e afetivo), o de organização e gestão (projeto instrucional adequado), o técnico (ajudar os alunos a se sentirem confortáveis com os recursos e ferramentas que configuram a proposta instrucional) ( $c f$. MAURI; ONRUBIA, 2010, p. 133).

${ }^{8}$ Endereço do Repositório Digital: http://www.elo.pro.br/cloud/.
} 
Figura 2: Página Inicial do ELO.

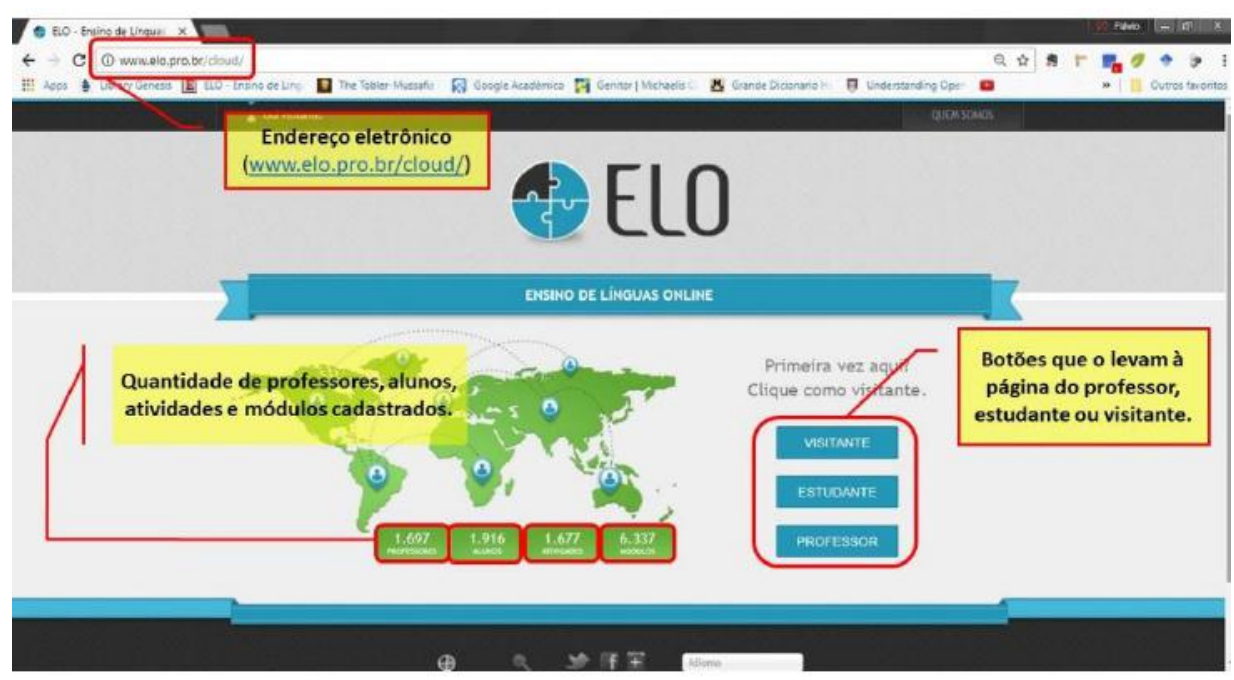

Fonte: http://www.elo.pro.br/cloud/.

Figura 3: Atividade 1 no ELO.
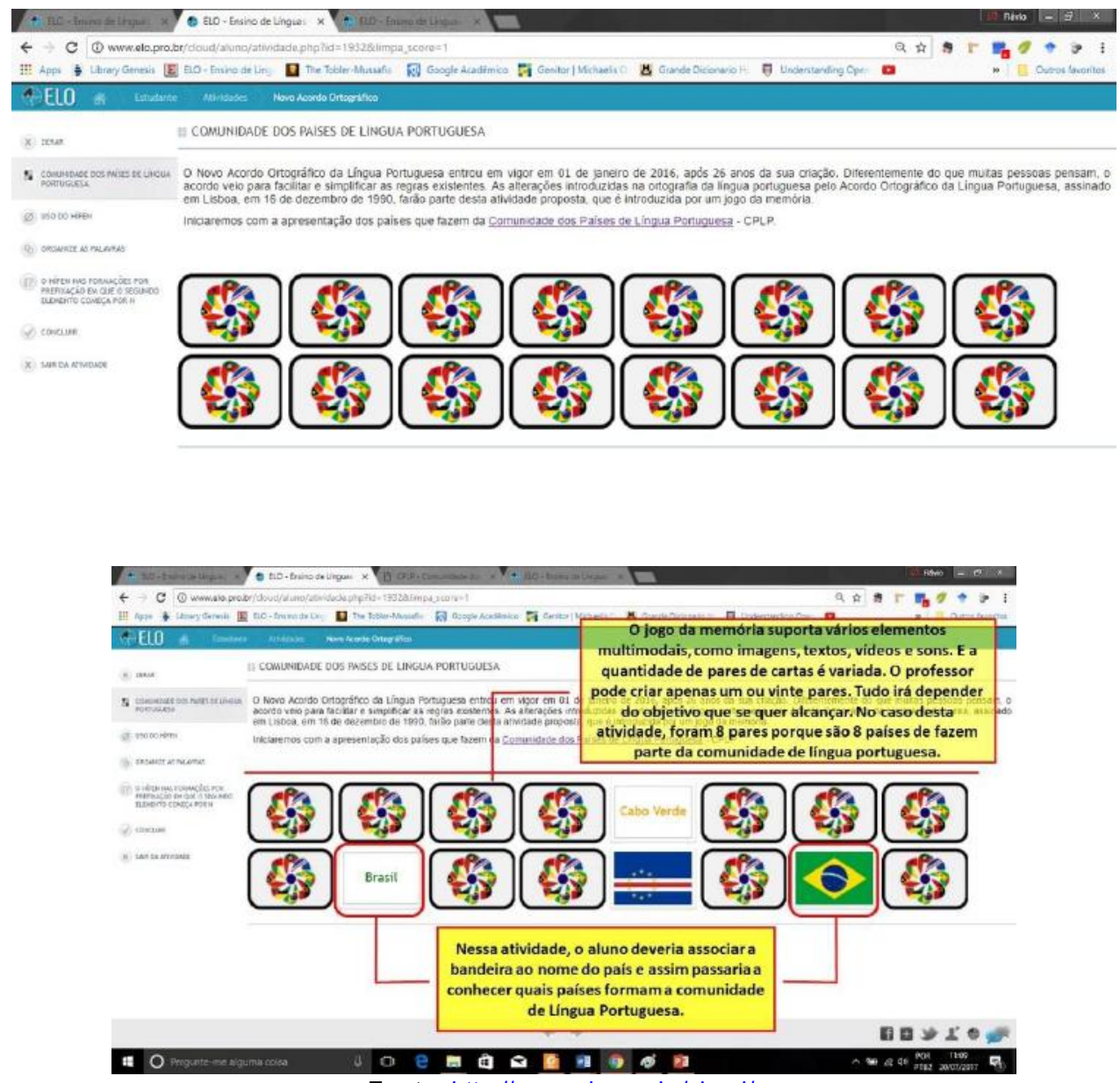

Fonte: http://www.elo.pro.br/cloud/. 
Figura 4: Atividade 1 no ELO.

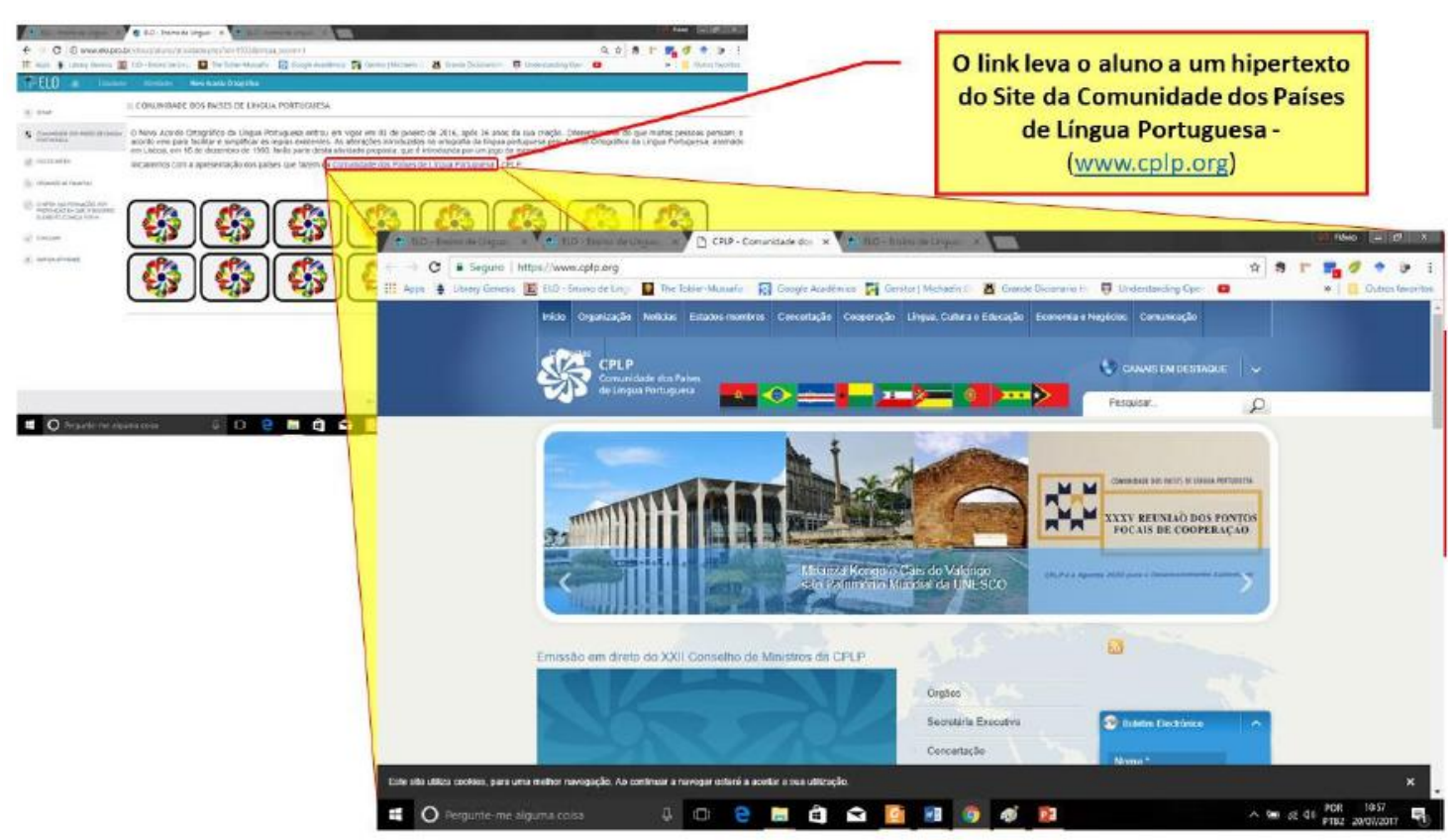

Fonte: http://www.elo.pro.br/cloud/.

O objetivo da atividade foi estimular o conhecimento dos alunos através do jogo, sobre os países que formam a Comunidade dos Países de Língua Portuguesa - CPLP - e, assim, compõem a comunidade que utiliza o Novo Acordo Ortográfico da Língua Portuguesa, como também a pesquisa online, que os remete a outro local na busca pela informação, para que possam relacionar as imagens de suas respectivas bandeiras e não, apenas, listar os nomes desses países. Há, assim, a necessidade de um conhecimento tecnológico, por parte dos alunos, no que se refere ao link que direciona para um hipertexto da CPLP. Os alunos, dessa forma, apropriavam-se, também, das habilidades técnicas do meio digital e adquiriam novos conhecimentos sobre essa comunidade linguística. 
Figura 5: Atividade 2 no ELO.

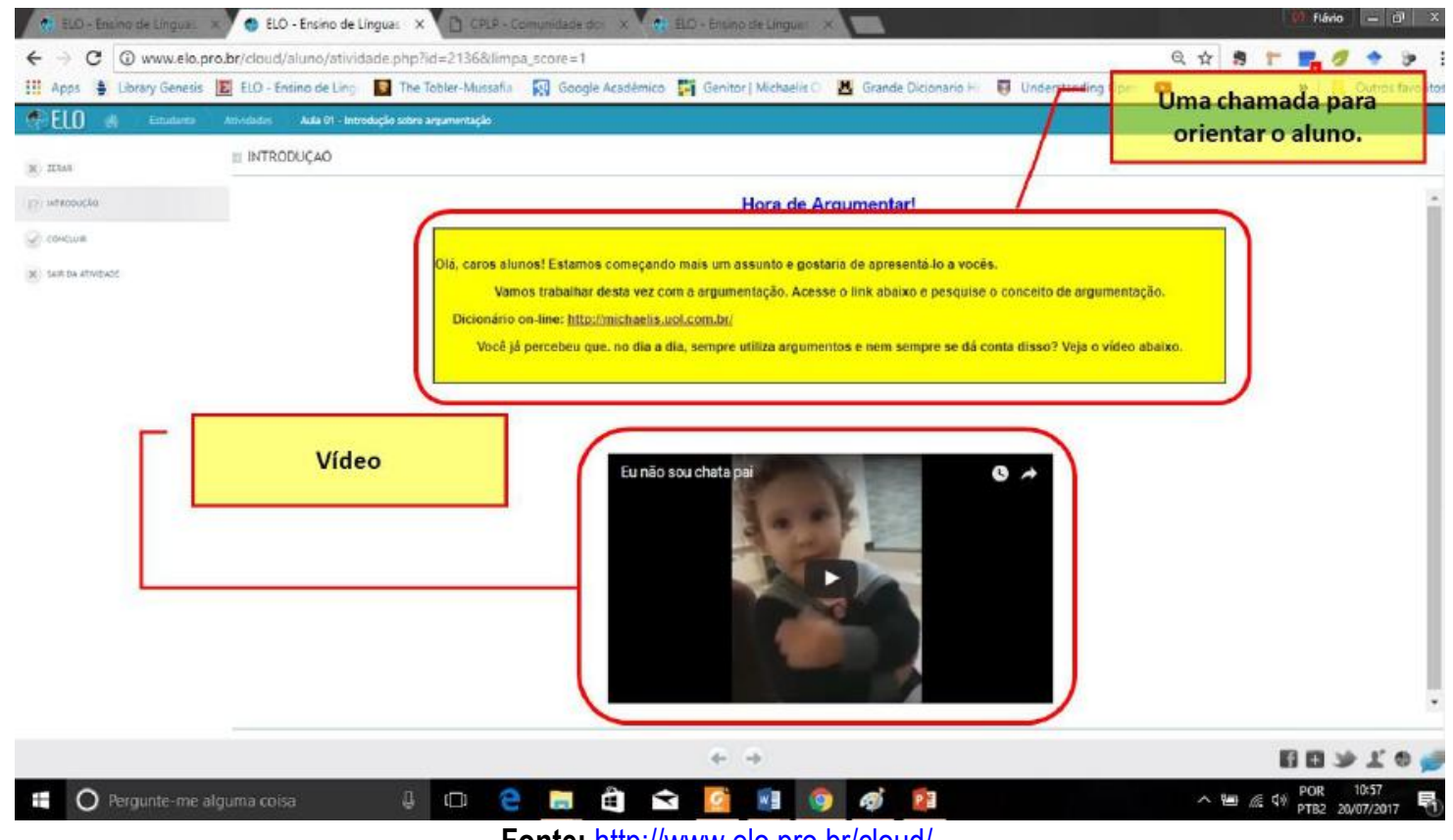

Fonte: http://www.elo.pro.br/cloud/.

A segunda atividade tinha por objetivo o aprendizado sobre um dos operadores argumentativos que utilizamos na Língua Portuguesa. A atividade continha instruções de pesquisa, vídeos e um QUIZ interativo. Essa atividade é bastante complexa no que diz respeito à sua elaboração e, consequentemente, demandava maior conhecimento por parte do professor da tecnologia e dos recursos tecnológicos disponíveis no ELO, ensejando dedicação maior na produção das possíveis respostas postadas pelos alunos, uma vez que o Quiz era interativo, possibilitando um diálogo com esses alunos na medida em que iam refletindo sobre a Língua Portuguesa, sobre as perguntas relacionadas ao vídeo e postando respostas, que poderiam ser adequadas ou não à situação visualizada, como podemos verificar na figura 5. Essas interações no Quiz configuram um termômetro para o professor da própria compreensão e reflexão dos alunos sobre a temática argumentação e suas peculiaridades gramaticais, textuais e discursivas.

Figura 6: Atividade 2 feedbacks do QUIZ.
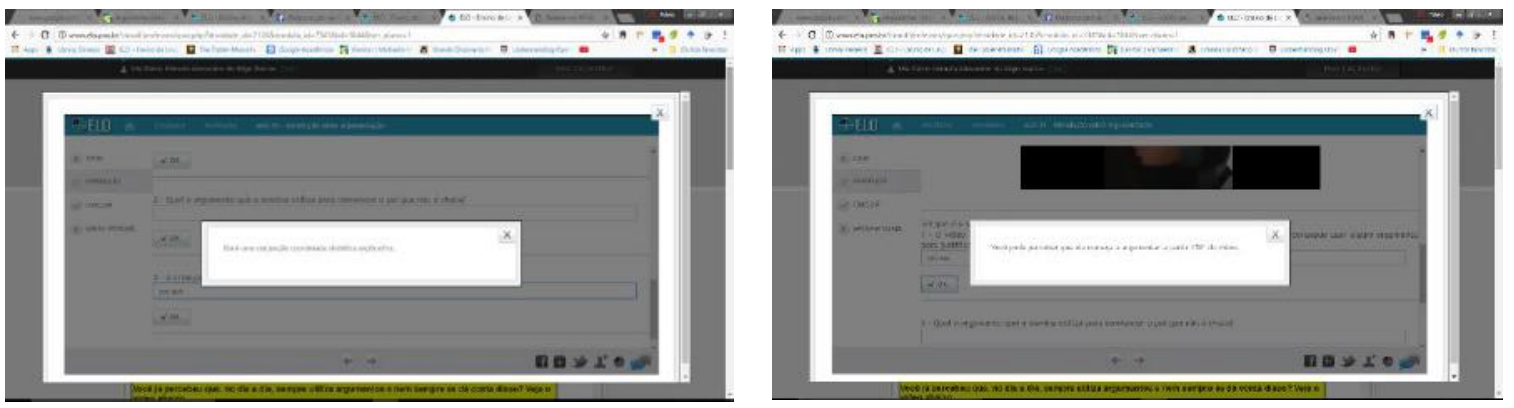


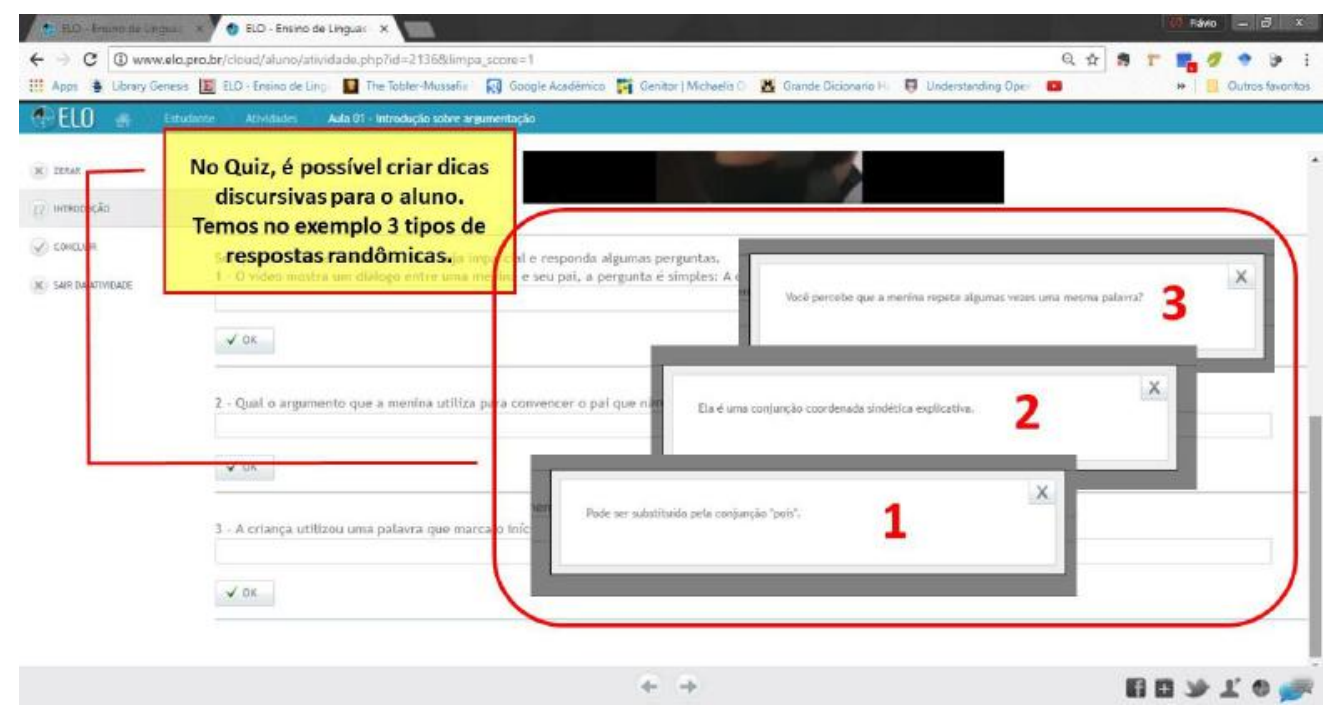

Observamos, assim, com base nas atividades 1 e 2, que o Repositório Digital ELO pode proporcionar ao aluno e ao professor: interação, reflexão, pesquisa online, construção do conhecimento, promoção de habilidades de navegação na Web 3.0, tudo ao mesmo tempo, possibilitando, ainda, o ensino de Língua Portuguesa em qualquer lugar. Isso só é possível porque sistemas complexos - recurso educacional aberto, ELO, Língua Portuguesa - foram interligados objetivando propiciar novas práticas pedagógicas digitais ao professor e novas experiências formativas ao aluno, favorecendo o ensinoaprendizagem de Língua Portuguesa.

\section{Conclusão}

Diante das teorias apresentadas e das atividades desenvolvidas, conclui-se que o REA é um grande aliado do professor na missão de ensinar. Representa outra possibilidade de acesso democrático à educação, de forma aberta e gratuita, interligada à Web 3.0, dentro do que propõe a TI. Os Recursos Educacionais Abertos utilizam-se da web semântica para desenvolver atividades pedagógicas mais atrativas, possibilitando a adaptação e tradução desses recursos, podendo compartilhá-los, remixá-los, reutilizá-los em diferentes contextos educacionais. As tecnologias digitais, com todos os recursos que as envolvem: os tabletes, smartphones, computadores, softwares, as redes sociais tornam-se meio de aprendizagem, meio esse dinâmico, envolvente e lúdico em favor da geração de conhecimento (CAIADO, 2011).

A utilização de sistemas tão heterogêneos e complexos parece não funcionar quando tratamos do ensino de Língua Portuguesa, entretanto é a integração da Linguagem, TDIC e Práticas Pedagógicas que proporcionarão um processo de ressignificação, um novo entendimento do ensino de LP, a partir da possibilidade de mudança de um estado de acomodação para a adaptação aos novos tempos. 


\section{Referências}

AGHAEI, S.; NEMATBAKHSH, M.A.; FARSANI, H.K. Evolution of the world wide web: From WEB 1.0 TO WEB 4.0. International Journal of Web \& Semantic Technology, v. 3, n. 1, 2012.

BALACHEFF, N. Didatique et intelligence artificielle. Recherches en didactique des mathématiques. Grenoble, La Pensée Sauvage, 1994a.

La transposition informatique: note sur un nouveau problème pour la didactique. In: ARTIGUE, M. et al. (Eds.). Vingt ans de didactique des mathématiques en France. Grenoble: La Pensée Sauvage, 1994b. p. 364-370.

BERNERS-LEE, Tim. Weaving the Web: the original design of the World Wide Web by its inventor. New York: Harper Business, 2000.

Semantic Web Road Map, 14 out. 1998. Disponível em https://www.w3.org/DesignIssues/Semantic.html. Acesso em: 12 de maio de 2016.

BECKNER, Clay et al. Language is a complex adaptative system: position paper. Language Learning, 59, Suppl. 1, 1-26, 2009. Disponível em http://cnl.psych.cornell.edu/pubs/2009-LACAS-pos-LL.pdf. Acesso em: 18 jul. 2017

BONILLA, M.H. Escola Aprendente: para além da sociedade da informação. Rio de Janeiro: Quartet, 2005.

. Escola Aprendente: comunidade em fluxo. Em: FREITAS, M.T.A. (Org.). Cibercultura e formação de professores. Belo Horizonte: Autêntica, 2009.

BUTCHER, Neil. A basic guide to open educational resources. British Columbia; Paris: Col. $\quad$ UNESCO, 2011. Disponível em http://www.col.org/resources/publications/Pages/detail.aspx?Pid=357. Acesso em $01 \mathrm{de}$ maio de 2016.

BYBEE, J. Language, usage and cognition. Cambridge: CUP, 2010.

CAIADO, R.V.R. Novas tecnologias digitais da informação e comunicação e o ensinoaprendizagem de língua portuguesa. Tese. Doutorado em Linguística, Universidade Federal de Pernambuco, Recife, 2011.

HUEY, E.B. The psychology and pedagogy of reading. Cambridge, MA: MIT Press, 1908.

LARSEN-FREEMAN, D.; CAMERON, L. Complex Systems and Applied Linguistics. Oxford Applied Linguistics. Oxford, UK: Oxford University Press, 2008.

Complex systems and applied linguistics. International Journal of Applied Linguistics, 17 (2), 226-239, 2007. 
LEFFA, V.J. Nem tudo que balança cai: objetos de aprendizagem no ensino de línguas. Polifonia, Cuiabá, v. 12, n. 2, 2006.

- Transdisciplinaridade no ensino de línguas: a perspectiva das teorias da complexidade. Revista Brasileira de Linguística Aplicada, v. 6, n. 1, 2006.

MOURI, T.; ONRUBIA, J. O professor em ambientes virtuais: perfis, condições e competências. Em: COLL, C.; MONEREO, C. (Orgs.). Psicologia da Educação Virtual: aprender e ensinar com as tecnologias da informação e da comunicação. Trad. Bras. Porto Alegre: Artmed, 2010. p. 118-135.

OLIVEIRA, R.A. de. Complexidade: conceitos, origens, afiliações e evoluções. Em: PAIVA, V.L.M. de O. (Org.). Sistemas Adaptativos Complexos. Belo Horizonte: Faculdade de Letras da UFMG, 2009.

PAIVA, V.L.M. de Oliveira e. Linguagem e aquisição de segunda língua na perspectiva dos sistemas complexos. Em: BURGO, V.H.; FERREIRA, E.F.; STORTO, L.J. Análise de textos falados e escritos: aplicando teorias. Curitiba: Editora CRV, 2011. p.71-86.

SANTOS, A.I. dos. Recursos educacionais abertos no Brasil: o estado da arte, desafios e perspectivas para o desenvolvimento e inovação. São Paulo: Comitê Gestor da Internet no Brasil, 2013.

Educação aberta: histórico, práticas e o contexto dos recursos educacionais abertos. Em: SANTANA, B.; ROSSINI, C.; PRETTO, N. De Luca. (Orgs.). Recursos Educacionais Abertos: práticas colaborativas e políticas públicas. São Paulo; Salvador: Casa da Cultura Digital; EDUFBA, 2012. Disponível em: http://livrorea.net.br. Acesso em 4 de março de 2013.

SANTOS, M. O que é a web 3.0? Qual sua importância para os negócios? Disponível em http://aquare.la/pt/artigos/2015/03/18/web-3-0-e-sua-importancia-nos-negocios/. Acesso em: 26 de maio de 2016.

WILEY, D. Connecting learning objects to instructional design theory: a definition, a metaphor, and a taxonomy. In: WILEY, D.A. (Ed.). The instructional use of learning objects [online version], 2000. Disponível em http://www.reusability.org/read/. Acesso em 01 de maio de 2016.

Artigo recebido em: julho de 2017.

Aprovado e revisado em: outubro de 2017.

Publicado em: novembro de 2017. 


\section{Para citar este texto:}

BARROS, Flávio Rômulo Alexandre do Rêgo; CAIADO, Roberta Varginha Ramos. Língua Portuguesa na web 3.0: relações complexas de ensino por meio dos Recursos Educacionais Abertos (REAs). Entremeios [Revista de Estudos do Discurso, on-line, www.entremeios.inf.br], Seção Temática [Linguagem e Tecnologia], Programa de PósGraduação em Ciências da Linguagem (PPGCL), Universidade do Vale do Sapucaí (UNIVÁS), Pouso Alegre (MG), vol. 15, p. 247-266, jul. - dez. 2017.

DOI: http://dx.doi.org/10.20337/ISSN2179-3514revistaENTREMEIOSvol15pagina247a266 